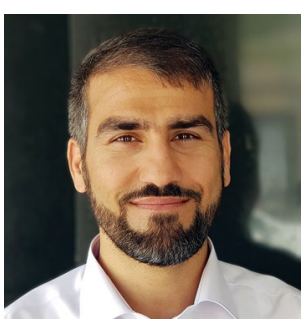

Credit: Mohammad Pakzad

\title{
Publication should not be a prerequisite to obtaining a PhD
}

\author{
Mandating publications for graduation places a poor metric on PhD students' skills and has \\ detrimental effects on PhD training, argues Sharif Moradi, an Assistant Professor at the Royan \\ Institute in Tehran; committees and future employers should focus on the many other skills \\ that PhD students master.
}

$\mathrm{D}$ espite many differences, universities and research institutes appear to have one thing in common: publish or perish. Publishing has benefits for many, including $\mathrm{PhD}$ students, as it increases the likelihood of finding academic positions. However, problems arise when $\mathrm{PhD}$ students are required to publish papers as a prerequisite for graduation. $\mathrm{PhD}$ students constitute an integral part of academia and are often required to publish one or more articles before submitting their dissertation. This is particularly true in my country, Iran, where students need to have one to three journal articles published or accepted for publication (depending on the university) before graduation.

There are several arguments, including among PhD students themselves, both for and against the publishing requirement for doctoral students. Although the publication requirement ensures that $\mathrm{PhD}$ projects are externally peer-reviewed, it may not necessarily enhance the quality of the work due to potential reviewer bias or ineffective peer review. This requirement may also call into question the reliability of the thesis reviewing committee if their evaluation is considered valuable only when the work has already been peer-reviewed (and published).

Due to their massive workloads, $\mathrm{PhD}$ students are under considerable stress and mental pressure, and publishing requirements can worsen this situation. Some students may be under financial pressure if they are underpaid-or worse, not paid at allespecially when they have to delay receiving their doctorates because of delays in getting published. As something that I personally experienced and think is globally true, many doctoral students live on earnings from teaching courses, translating texts from one language to another, or other low-paying jobs. Supervisors may be opposed to this, since it distracts students from working on their thesis and increases the pressure they're under. Students may end up publishing a lowquality paper in a low-profile journal, or even in fake and predatory journals which publish papers for a fee without rigorous peer review.
$\mathrm{PhD}$ mentors often have other priorities and concerns-such as finding funding, securing a permanent position, and coping with excessive administrative burdens-so often they cannot allocate enough time to their PhD students. Mentors may even engage $\mathrm{PhD}$ students in side projects to accelerate those projects, thereby delaying their graduation. Therefore, $\mathrm{PhD}$ students need to learn to say no to whatever distracts them from their thesis, although this might be sometimes difficult because $\mathrm{PhD}$ students are much more vulnerable than their supervisors to the consequences of potential conflicts. I believe $\mathrm{PhD}$ studentship is exactly the time during which people should learn how to maintain a healthy work-life balance, because this skill is more difficult to learn later.

$\mathrm{PhD}$ students should be encouraged to publish their $\mathrm{PhD}$ work after graduation (if it is not feasible to publish before graduation) because this indicates that they are able to take a project from beginning to completion and to advance their field of research. However, other criteria should be taken into consideration when assessing $\mathrm{PhD}$ students for their graduation, such as the ability to effectively defend their results before an unbiased, knowledgeable committee of referees or developing a product or service from their $\mathrm{PhD}$ project. There may be mitigating factors: for example, the $\mathrm{PhD}$ work needs more time to complete, is scooped by publications from other groups, turns out to be less relevant than initially thought or cannot be published due to intellectual property reasons. Therefore, it makes no sense to make graduation dependent on journal publication.

Both students wishing to remain in academia and students aiming for industrial careers need to learn many skills. Obviously, for students who want to work in industry, published papers are not crucial. But I think the same should be true for students who want to pursue academic careers. They, too, need to learn many skills, which they can demonstrate with or without publications to those in hiring positions. In assessing a postdoctoral applicant for a role in my lab,
I would examine the tone and content of their application email, what achievements are listed on their CV (e.g., awards, grants and publications) and check in personally with their referees. Key questions to referees would be whether the applicant is passionate, detail-oriented, motivated, innovative, a team player and committed. What is the applicant's personality and attitude? This is important as it is something that is hard to change. At interview, I would ask the applicant to give a chalk talk (or slide presentation) to analyse, in addition to their presentation skills, the strength of the applicant's scientific reasoning and how he or she deals with criticism. The applicant should be familiar with management (time, budgets and projects) and communication skills (writing, speaking and networking). Applicants that have international experience and know how to organize meetings and symposia would be more interesting to me. Only after all these assessments would I question why an applicant has not yet published any papers from their thesis.

In situations where publishing a paper is still mandatory, I recommend that $\mathrm{PhD}$ projects be designed strongly, assigned to a team of researchers instead of a single person, quickly modified or changed if they appear not to be working, and effectively supervised by mentors. I would certainly encourage PhD students to get published, but think the disadvantages of a publication mandate for graduation of $\mathrm{PhD}$ students far outweigh its advantages. I would never assess a PhD student solely on the basis of their publications, or lack thereof.

\section{Sharif Moradi}

Department of Stem Cells and Developmental Biology, Cell Science Research Center, Royan Institute for Stem Cell Biology and Technology, ACECR,

Tehran, Iran.

e-mail:sharif.moradi@royaninstitute.org

Published online: 10 October 2019 https://doi.org/10.1038/s41562-019-0690-7

Competing interests

The author declares no competing interests. 